\title{
GCU
}

Glasgow Caledonian

University

University for the Common Good

\section{Assessing the effect of Independent Prescribing for community optometrists and referral rates to Hospital Eye Services in Scotland}

El-Abiary, Mariam; Loffler, Gunter; Young, David; Strang, Niall; Lockington, David

Published in:

Eye

DOI:

10.1038/s41433-020-1095-6

$10.1038 / \mathrm{s} 41433-020-1095-6$

Publication date:

2021

Document Version

Author accepted manuscript

Link to publication in ResearchOnline

Citation for published version (Harvard):

El-Abiary, M, Loffler, G, Young, D, Strang, N \& Lockington, D 2021, 'Assessing the effect of Independent

Prescribing for community optometrists and referral rates to Hospital Eye Services in Scotland', Eye, vol. 35, no.

5, pp. 1496-1503. https://doi.org/10.1038/s41433-020-1095-6, https://doi.org/10.1038/s41433-020-1095-6

\section{General rights}

Copyright and moral rights for the publications made accessible in the public portal are retained by the authors and/or other copyright owners and it is a condition of accessing publications that users recognise and abide by the legal requirements associated with these rights.

Take down policy

If you believe that this document breaches copyright please view our takedown policy at https://edshare.gcu.ac.uk/id/eprint/5179 for details

of how to contact us. 
Assessing the effect of Independent Prescribing for community optometrists and referral rates to Hospital Eye Services in Scotland

\section{Authors:}

Mariam El-Abiary, Gunter Loffler, David Young, Niall Strang, David Lockington

Corresponding author: David Lockington; davidlockington@hotmail.com

\section{Affiliations:}

ME, DL: Tennent Institute of Ophthalmology, Gartnavel General Hospital, 1053 Great Western Road, Glasgow, UK, G12 OYN

GL, NS: Department of Vision Sciences, School of Health and Life Sciences, Cowcaddens Road, Glasgow, G4 OBA

DY: Department of Mathematics and Statistics, University of Strathclyde, 16 Richmond Street, Glasgow, UK, G1 1XQ

Phone: (+44) 1412111643

Fax: 01412112054

Word Count: 3346

Keywords: Optometrist, primary care, referral rates, supplementary examinations, costs, IP, independent prescribing, capacity, GOS

Conflict of interest: none

Permission for publication: granted

Acknowledgments: A version of this study won best poster presentation at the Scottish Ophthalmological Club meeting in Stirling, Scotland, in September 2019. 


\begin{abstract}
Introduction

Since 2010, General Ophthalmic Services (GOS) legislation and Independent Prescribing (IP) enable community optometrists to manage primary eye conditions. No studies have assessed the effect of IP. We wished to determine the distribution of IP optometrists and associated hospital referral rates across Scotland.
\end{abstract}

\title{
Methods
}

In 2019, FOI requests (General Optical Council and NHS Education Scotland) identified all registered IP optometrists in Scotland and their registered postcodes. Data regarding community eye examinations and referrals to HES since 2010 was gathered via Information Services Division of NHS Scotland.

\section{Results}

As of March 2019, there were 278 IP optometrists in Scotland (23.4\%). 218 IP optometrists work in 293 practices across 11 of Scotland's 14 health boards. There was a strong correlation $(r=+0.96)$ between population density and number of IP optometrists. 56\% of IP optometrists work in the two most deprived quintiles. Since IP's introduction, there has been a marked increase in anterior segment supplementary visits (+290\%). Optometry referrals to GPs have reduced by $10.5 \%$, but referrals to HES have increased by $118 \%$ (to 96,315 ). There was no correlation between quantity of IP optometrists and referral rates to HES $(r=-0.06,95 \% \mathrm{Cl}-0.64$ to $0.56, p=0.86)$.

\section{Conclusion}

This is the first analysis of IP optometrists and associated referral rates in Scotland. Despite good geographical distribution and increased supplementary attendances, optometric referrals to HES have doubled and continue to rise. We propose a ratio of primary, supplementary, non-referral and referral rates to discern the true impact of IP versus non-IP community optometric behaviour.

\section{Word Count: 249}




\section{Introduction}

Consistent with an expanding and ageing population, demand on the hospital eye services (HES) continues to increase significantly. In light of this, the Scottish Government implemented the extended General Ophthalmic Services (GOS) legislation in 2010, with the aim of reducing the burden on GPs and HES. This shifted the contact point for primary eye care towards community optometrists, who became the designated first port of call for primary and unplanned eye care provision. ${ }^{12}$

Eye examinations carried out by community optometrists are divided into primary and supplementary examinations, attracting separate reimbursement charges. Primary examinations are regular standard testing, performed at established intervals depending on patient age and known ocular diagnoses, whereas supplementary examinations are performed outside and in addition to these established intervals. This type of activity is separate from the 5 categories for routine primary eye care examinations. Supplementary examinations can involve an initial ocular assessment or be a review of disease progress or management. As providing ongoing management of primary eye conditions was a change in established optometric behaviour, new supplementary codes were introduced in conjunction with the new legislation in 2010. ${ }^{3}$ In September 2018, enhanced supplementary codes were introduced to reflect the additional time required for clinical assessments such as those requiring pupil dilation. [See Supplementary Table 1 online for details of codes]

To provide appropriate oversight to this sea-change in traditional optometric activity, the General Optical Council (GOC) introduced a specialist register for Independent Prescribing (IP) optometrists who have completed accredited theoretical training, a hospital placement under the supervision of an ophthalmologist and a final exam. ${ }^{45}$ As a result of achieving this qualification, IP optometrists can now prescribe appropriate medications and manage patients with ophthalmic conditions in the primary care setting within their sphere of confidence. This development was intended to potentially reduce avoidable hospital-based ophthalmology appointments. ${ }^{6}$ The IP handbook produced by the GOC expects that practitioners who hold the IP qualification will mainly work in primary care and glaucoma. ${ }^{6}$

With financial support from NHS Education Scotland (NES), an ever-increasing cohort of optometrists in Scotland have become IP qualified and been added to the GOC IP register. Despite IP being introduced nearly 10 years ago, there is no published literature about its' effectiveness. An initial survey found that up to $96 \%$ of IP optometrists managed blepharitis and dry eye presentations comfortably, however only $14 \%$ supplied topical antibiotics. ${ }^{7}$ Another survey looking at the attitudes 
and behaviours in a small cohort of 39 IP optometrists in 2011 found that 51\% reported that they were referring less patients to secondary care, while $41 \%$ reported no noticeable difference in their referring behaviour. ${ }^{8}$

The purpose of this study was to identify and evaluate the distribution of IP optometrists across Scotland in 2019 by health board, population served and social deprivation score. We also wished to objectively assess the impact of IP on referral rates into HES since 2010 by analysing the currently available information regarding community optometry behaviour. 


\section{Methods}

Following the introduction of the Scottish Eyecare Integration Project, electronic referrals allow easily accessible national statistics for ophthalmic professionals and policy makers regarding community eyecare in Scotland. ${ }^{9}$ Current and historical data pertaining to community optometry visits and outpatient hospital attendances since 2010 was obtained from the Information Services Division (ISD), an online statistics warehouse which forms part of NHS Scotland. ${ }^{10}$

Through freedom of information (FOI) requests to the GOC and NES in March 2019, a list of all the currently registered IP optometrists in Scotland with their respective practice addresses (postcodes) was obtained. This was divided into Scotland's 14 health boards, then correlated with the population served by each board to determine the distribution nationally and locally.

To define the distribution of IP optometrists based on deprivation, each address was entered into the Scottish Index of Multiple Deprivation (SIMD 2016) map to convert the post code into a deprivation score. This online tool divides Scotland into 6976 data zones which are ranked $(1=$ most deprived to 6976 = least deprived) based on income, employment, education, health, access to services, crime, and housing. The deprivation scores assigned to each address was divided into quintiles ( $1=$ most deprived quintile and $5=$ least deprived quintile), similar to the 2017 Legge et al study which had identified the distribution of all community optometrists in Scotland. ${ }^{11}$

The percentage share of IP optometrists was calculated by dividing the number of IP optometrists in one health board by the total number of IP optometrists in Scotland. ${ }^{7}$ Similarly, population share was calculated by dividing the number of SIMD data zones in a health board by the total number of data zones in Scotland.

To assess the spread of IP optometrists in each quintile, the coefficient of skewness was calculated for each health board. This is a measure of how symmetrically IP optometrists are distributed. A negative coefficient of skew would indicate a preponderance of IP optometrists in the least deprived quintiles (Q4 and Q5), whereas a positive coefficient would indicate more IP optometrists in more deprived quintiles (Q1 and Q2). A value between -0.5 and +0.5 would suggest an almost symmetrical distribution in both extremes of deprivation, and a value above +1 or below -1 would indicate a highly skewed distribution. The Pearson correlation coefficient was used to assess the association between two continuous variables with a linear relationship. A $p$ value of $<0.05$ was considered statistically significant, and confidence intervals were set at $95 \%$. All statistical analysis was conducted using MedCalc Statistical Software 19.2.3 (MedCalc Software Ltd, Ostend, Belgium). 


\section{Results}

Quantity and Distribution of IP Optometrists in Scotland in 2019

As of March 2019, there were 1189 community optometrists in Scotland, with 278 registered as holding the IP qualification (23.4\%). According to the GOC register, a total of 218 IP optometrists registered 293 working addresses in Scotland. Sixty IP optometrists provided either a hospital address or did not provide a community address. These were excluded from our community-based geographical analysis as hospital-based optometrists neither carry out GOS eye examinations (including supplementary exams) nor refer to the HES.

Figure 1: Graph showing the percentage share of IP optometrists in each quintile of deprivation (Q1-5) in each health board in 2019. There were no IP optometrists in NHS Orkney, NHS Shetland and NHS Western Isles. The addition of all the bars in one quintile equals $100 \%$. The coefficient of skewness below demonstrates the degree of symmetry of IP optometrists across quintiles of deprivation in each health board.

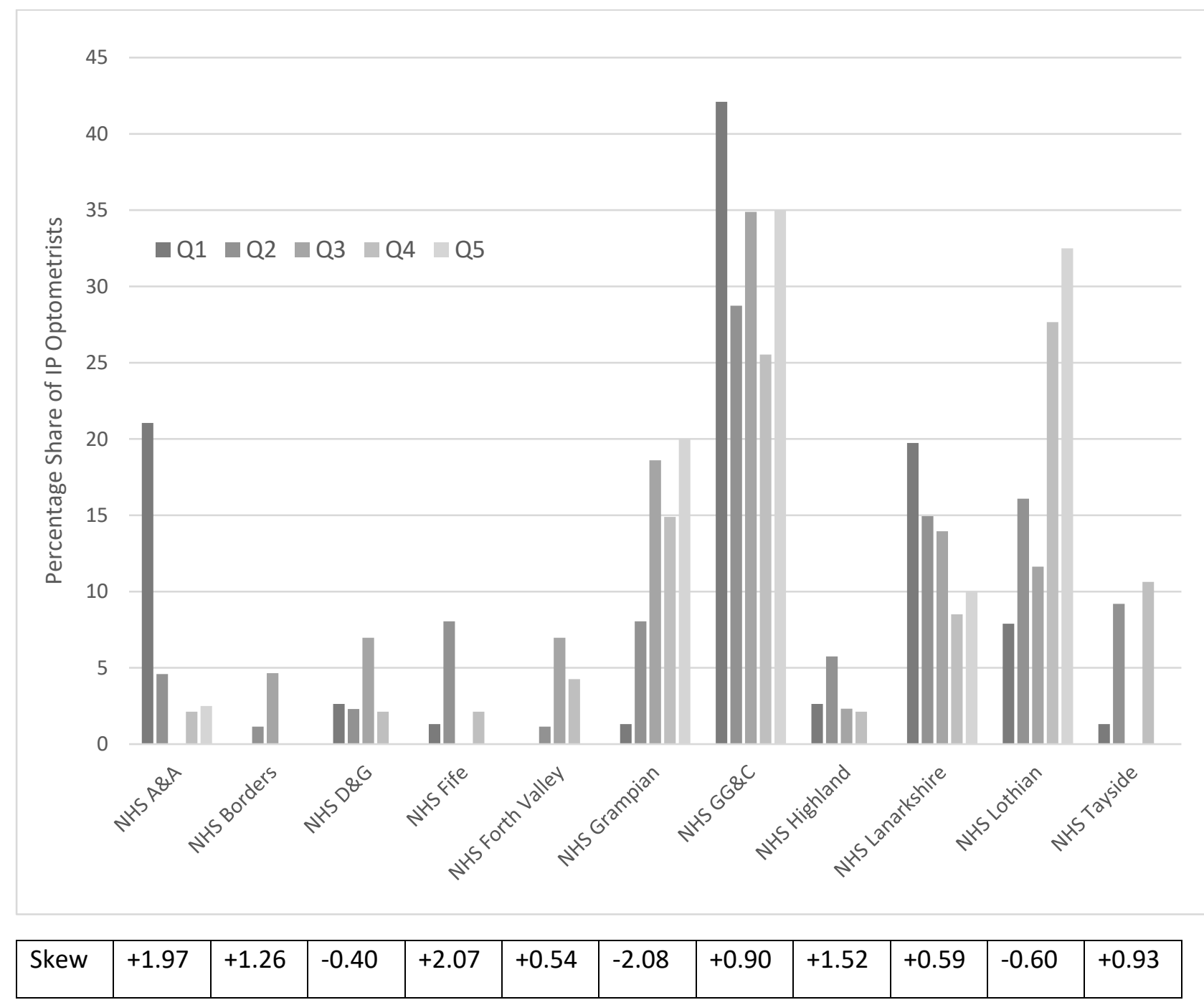


There was a small over-representation of IP optometrists in population-rich health boards (NHS Grampian, NHS Lanarkshire, NHS Lothian and NHS GG\&C) and an under-representation in the smaller ones (NHS Borders, NHS Fife, NHS Forth Valley and NHS Tayside). Across Scotland, the distribution of IP optometrists showed a significant correlation with population share (correlation coefficient $r=+0.96, \mathrm{Cl} 0.85$ to $0.99, \mathrm{p}<0.01)$. For this analysis, three of Scotland's fourteen health boards (NHS Orkney, NHS Shetlands and NHS Western Isles) were excluded as they did not to have a registered IP optometrist according to the data gathered in March 2019. IP optometrists were slightly over-represented in the two most deprived quintiles in Scotland, with NHS A\&A, NHS GG\&C and NHS Lanarkshire all appearing to have a greater percentage share of IP optometrists in the most deprived quintile. Looking at the coefficient of skewness, NHS A\&A, NHS Borders, NHS Fife and NHS Highland had the highest positive skew values, indicating a preponderance of IP optometrists in more deprived areas. By contrast, IP optometrists in NHS Lothian and NHS Grampian were more frequently found in the least deprived quintiles. [See Figure 1 for a snapshot of the distribution of all IP optometrists in Scotland in 2019, divided by health board and quintile of deprivation]

\section{Primary and Supplementary Eye Examinations}

There has been a $18 \%$ increase (from $1,497,764$ to $1,763,659$ ) in the number of primary optometric examinations since 2010. Over the same period, supplementary exams have increased markedly by 93.2\% (from 300,196 to 579,945 ). Overall, there has been a $30.3 \%$ increase in the total number of eye examinations performed by community optometrists in Scotland since 2010 (from 1,797,960 to $2,343,604)$. [See Supplementary online Figure 1 for yearly breakdown] The greatest increases in supplementary eye examinations involved anterior segment presentations (from 47,294 to 184,678; percentage change $+290 \%$ ) and visual / neurological symptoms (from 114,590 to 213,687 ; percentage change $+86.5 \%$ ). Together these make up $68.7 \%$ of all supplementary visits in $2018 / 19$ (total number of supplementary exams 579,945). [See Figure 2 which illustrates the increasing trend in supplementary visits to community optometrists since 2010 , and the increase in anterior segment reviews, which may relate to an IP effect]

\section{Optometric Referrals to Hospital Eye Services}

According to the ISD statistics, the referral rate from community optometry to HES has increased from $2.5 \%$ in $2010 / 11$ to $4.1 \%$ in 2018/19 throughout Scotland. The greatest increase was seen in NHS GG\&C (from 8,597 to 23,666; average annual rate change $+10.8 \%$ ) and the lowest increase was seen in NHS Forth Valley (from 2,974 to 4,504; average annual rate change $+2.2 \%$ ). [See Figure 3 for yearly breakdown per healthboard] When the referral rate in each of the 14 health boards was plotted against the percentage of optometrists who held the IP qualification in 2019, there was no 
discernible association that the quantity of IP optometrists reduced the referral rate to HES (Pearson correlation co-efficient $r=+0.53,95 \% \mathrm{CL}-0.002$ to $0.82, p=0.052$ ). [See Figure 4 ] When we excluded the 3 health boards with no IP optometrists, the statistical results were $\operatorname{similar}(r=-0.06,95 \% \mathrm{Cl}-0.64$ to $0.56, p=0.86$ ). These results illustrate that there was no correlation identified between the percentage of IP optometrists and the referral rate.

Figure 2: Graph illustrating the four commonest recorded reasons for supplementary visits since 2010. Anterior segment presentations and sudden visual loss / flashes \& floaters / neurological symptoms represent $68.7 \%$ of all supplementary examinations in $2018 / 19$. Average annual increase is shown on the right. Other recorded reasons for supplementary visits have been excluded as they each make up less than 20,000 visits per year.

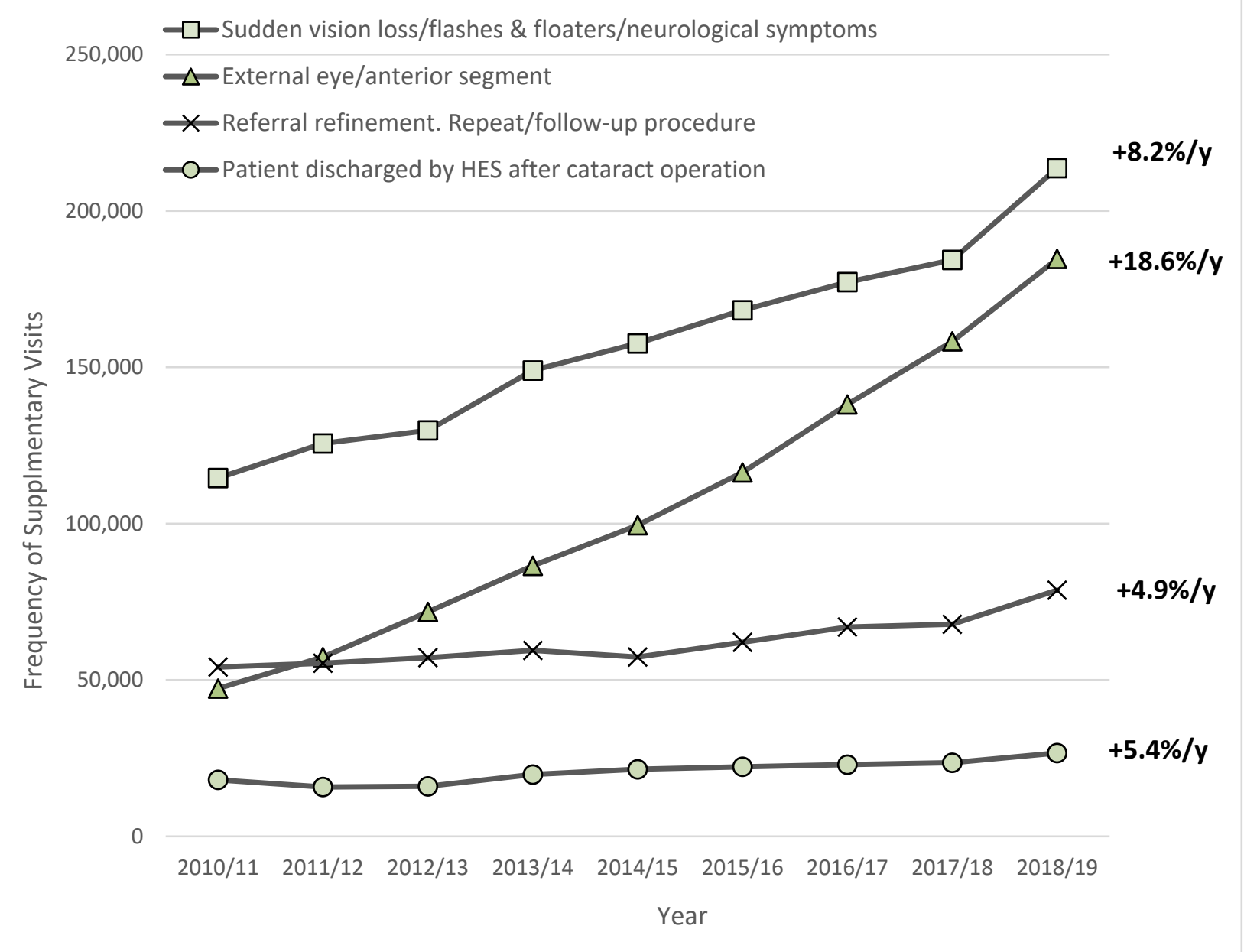


Figure 3: Graph showing the increase in referral rates from community optometry to HES in each health board since 2010. The referral rate for the whole of Scotland has increased from $2.5 \%$ to 4.1\%. The greatest increase was seen in NHS GG\&C and the smallest increase in NHS Forth Valley.

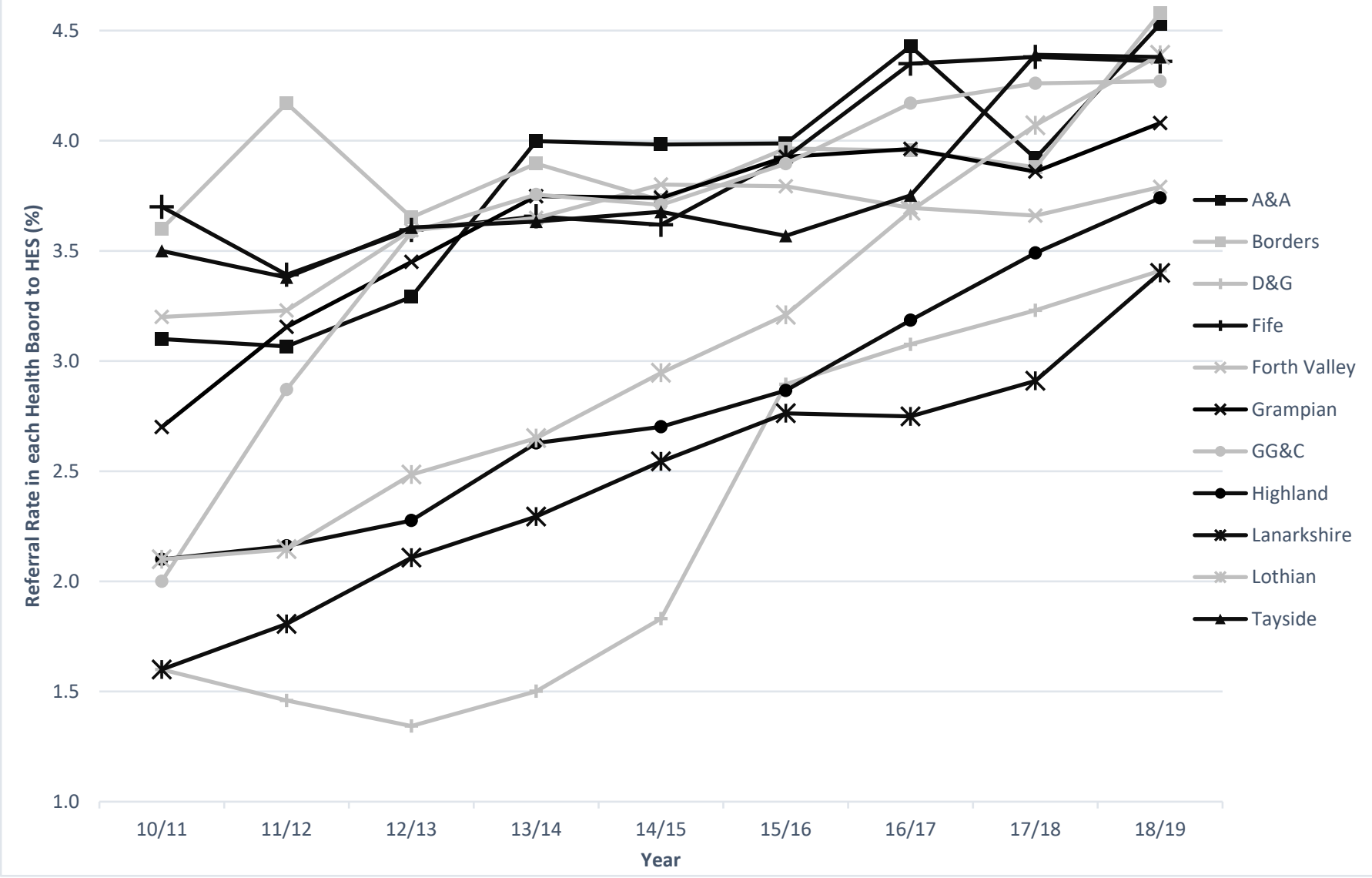

Figure 4: Graph showing the correlation between referral rate to HES and the percentage of optometrists who hold the IP qualification for each health board in 2018/19. For all 14 health boards (solid trendline), the Pearson correlation was not significant, $r=+0.53,95 \% \mathrm{Cl}-0.002$ to 0.83, $p=0.052$. Excluding the three health boards with no IP optometrists (dashed trendline), Pearson correlation was $r=-0.06,95 \% \mathrm{Cl}-0.64$ to $0.56, p=0.86$ (still not significant).

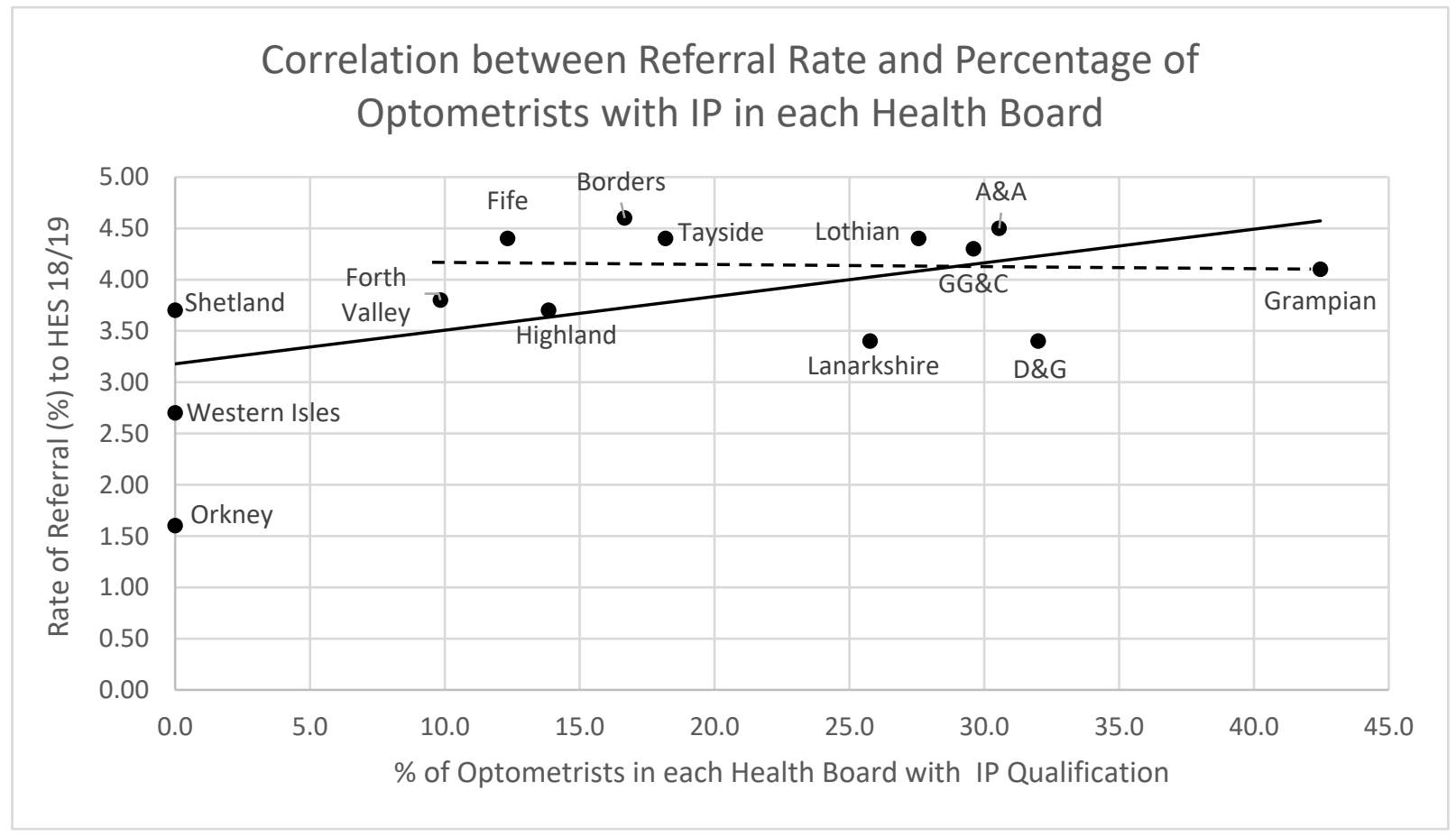


Figure 5: Graph showing absolute numbers of community optometry referrals to HES and the number of new patient attendances in HES. The average annual increase in referrals $(\mathbf{1 4 . 8 \% )}$ was not mirrored by a similar increase in new patient HES attendances $(1.8 \%)$. This may be suggestive of a lack of capacity / resources in HES.

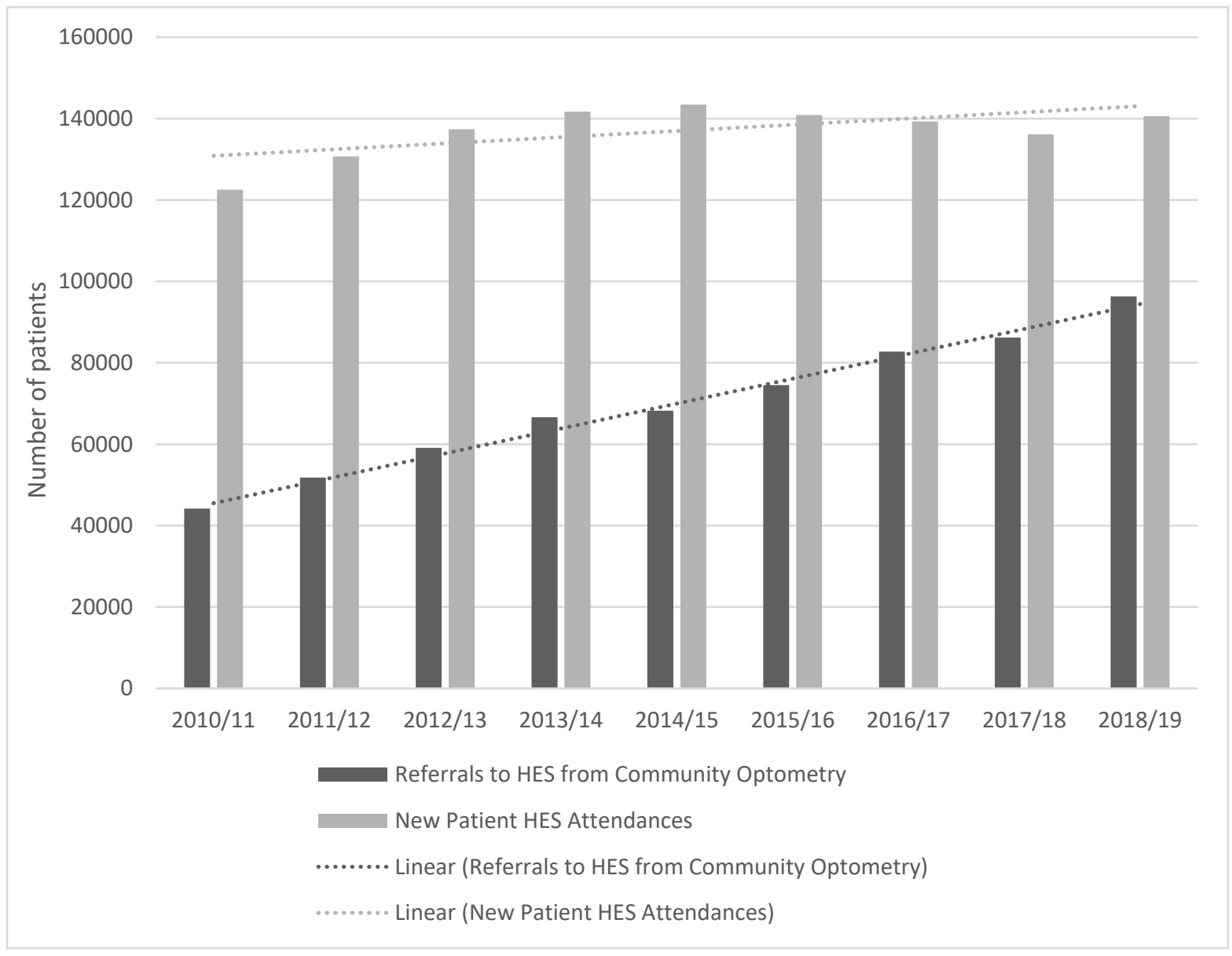

In terms of absolute numbers, referrals from optometrists to HES increased from 44,174 referrals in $2010 / 11$ to 96,315 in $2018 / 19$. This increased demand was not matched by increased capacity in the HES, as available "New Patient" appointments have only increased by $14.7 \%$ in this time period (from 122,538 to 140,5997 ). This mismatch was further illustrated by the finding that there was a $14.8 \%$ annual rise in optometry referrals to HES, but only a $1.8 \%$ annual rise in new patient attendances in HES. [See Figure 5] 


\section{Discussion}

Displacing primary eye care services from the hospital eye services (HES) into community optometry was intended to address the existing capacity and demand issues within ophthalmology. Community optometry benefits from ease of local access for patients, potential for accessible diagnostic technology and a more detailed referral to HES when required. IP was intended to further develop this pathway, through providing prescribing capabilities and local management to avoid unnecessary HES attendance. ${ }^{5}$

Our paper identified a $23.4 \%$ uptake of IP within optometrists in Scotland. In addition to Northern Ireland and London, Scotland already benefits from larger numbers of optometrists compared to the rest of the UK. ${ }^{12}$ Similar to Legge et al who investigated the distribution share of all optometrists in Scotland, our study also found a strongly positive correlation between the location of IP optometrists and the population served in each health board. NHS GG\&C has the largest population density of all the health boards in Scotland, so it is unsurprising that it has the largest number of IP optometrists. This may in part be due to the location of Glasgow Caledonian University, which provides the optometric training for undergraduate and IP level qualifications. A similar pattern has been observed across the UK with recruited students and qualified optometrists clustering around the locations of undergraduate training providers. ${ }^{12}$

According to the SIMD scores, the most deprived areas in Scotland are centred around Glasgow City, and the three health boards with the greatest deprivation indices are NHS GG\&C, NHS A\&A and NHS Lanarkshire ${ }^{13}$ All of these areas showed a comparative over-representation of IP optometrists compared to elsewhere in Scotland. What the data does not show is the underlying distribution of quintiles in each health board. If those have an underlying skew (i.e., more post codes in the lower compared to higher quintiles in NHS GG\&C) then this will also have an impact on the distribution of IP optometrists.

It should be noted that our analysis only describes how IP optometrists are distributed across Scottish health boards. It does not make any judgment or suggestion with regards to what may be an appropriate number of IP optometrists per population.

The demand for community eye care is rising due to population demographics, chronic eye conditions, ongoing patient education, occupational requirements and follow-up of patients discharged from HES and shared care schemes. ${ }^{3} \mathrm{GOS}$ legislation focused on managing eye patients in the community and improving the quality of HES referrals, an anticipated streamlining and reduction of referrals. ${ }^{14}{ }^{15} \mathrm{It}$ follows that one would expect an increase in supplementary examinations to reflect the combination of community optometrists adopting the role of primary 
care providers, and IP allowing optometrists to initiate treatment and generate additional supplementary visits to follow up treatment responses. Our study identified a significant increase in supplementary visits coded as anterior segment (290\%) and new visual/neurological symptoms (86.5\%), which made up $68.7 \%$ of all such (presumed acute) visits. The yearly increase in supplementary visits was significantly higher for anterior segment presentations (32.2\% per year) compared to visual / neurological symptoms ( $8.7 \%$ per year). One possible explanation for this is that visual / neurological symptoms are likely to generate a direct referral onto HES, whereas a proportion of anterior segment complaints could be managed by an IP optometrist. This will generate further supplementary visits to monitor treatment response. Undoubtedly, there will be some variability in the number of supplementary visits generated depending on optometrists' experience. As this paper is purely descriptive of optometric behaviour, we cannot make any comments as to the reasons or justification for the quantity of supplementary visits being undertaken in this time period.

It is unclear from these figures if the increased optometry visits are limiting a similar rise in new patient HES attendances (which would suggest that community optometry can negate the need for HES referral). The comparatively small increase in new HES visits may more reflect the lack of resources and capacity in the HES, as outpatient waiting times in ophthalmology continue to rise. ${ }^{16}$ During the same 10 year time period, outpatient attendances have increased by $38 \%$ in England, compared to only $9.8 \%$ in Scotland. ${ }^{17}$ It is uncertain how much IP behaviour in Scotland contributes to this, as HES referrals continue to rise in Scotland despite the advent of IP. For example, one may hypothesise that having more IP optometrists would be associated with a lower referral rate to HES. This was not seen to be the case, as illustrated in Figure 4, demonstrating that the quantity of IPqualified optometrists was not associated with a reduction in referrals to HES.

There are multiple factors to consider when assessing the quality, quantity and indications for referrals from optometry to HES, which are beyond the scope of this article. It has been reported that concordance is high (76\%) between optometry referrals and diagnoses by ophthalmologists in the UK. ${ }^{18}{ }^{19} \mathrm{~A}$ more recent study analysed the level of agreement between IP optometrists and consultant ophthalmologists in the acute hospital ophthalmic services, and found concordant prescribing and decision making whenever IP optometrists were experienced and appropriately trained. ${ }^{20}$ Where safe and appropriate, it is these acute cases that can be managed in the community. But it is important to acknowledge that diagnostic uncertainty generates HES referrals too, which may indicate that further training is required to help minimise unnecessary referrals. Lack of feedback for optometrist referrals has been reported as a barrier to education and referral improvement. ${ }^{21}$ In 2005, Evans et al highlighted that despite a written request for feedback, only 
$13 \%$ of ophthalmologists provided this. ${ }^{22}$ An accessible electronic patient record system may address this in the future. The Royal College of Ophthalmologists published the joint Ophthalmic Services Guideline with the College of Optometrists stating that there needs to be robust communication between community optometrists and the HES to deliver high quality care. ${ }^{23}$

A major contributing factor to increasing HES referrals could simply be that the rising demand in the older demographic of patients. $46 \%$ of all community eye examinations involve patients over the age of $60 .{ }^{10}$ As age related eye conditions become more prevalent, it is not surprising that more patients require referral to HES, influencing the referral rate. 


\section{Limitations}

As this is the first analysis of community IP optometry in Scotland, there are acknowledged limitations. There were 60 IP optometrists in Scotland that were excluded from this analysis, as they did not provide a community address. Of note, it is not mandatory to provide a working address for the GOC register. Similar to Legge et al, we also assumed that patients reside in the same data zone as the optometrists' address. It could be that these optometric services are more likely to be based in central or high street locations. Our analysis did not map the locations of community premises where IP optometrists are based like Low et al did in NHS Tayside. ${ }^{24}$ Variability in deprivation in a defined area can mean that the distribution of IP optometrists does not necessarily reflect the true SIMD demographic of all the patients utilising that service. As our study evaluated IP optometry in the community, we excluded those health boards which had no IP optometrists to keep the data more specific. The 3 health boards without IP optometrists serve small populations over a relatively scattered geographical area, so cannot be used as an accurate benchmark for non-IP optometry practice. However, this exclusion did not alter the statistical results. [See both trendlines in Figure 4]

The referral data was non-specific in nature, and not separated in terms of clinical urgency (i.e. whether destined for acute referral clinics, urgent or routine outpatient clinics).

Our study does not evaluate the prescribing habits or behaviour of IP optometrists, nor does it include a cost-benefit analysis following the introduction of IP. It only analyses the quantity rather than the quality of referrals. As demand continues to rise, further work is advised to assess these factors, as well as the patient perspective, as this data will be required for future planning. From our limited and specific analysis, we are unable to make any comment or recommendations as to the indications or requirements for repeat supplementary examinations, and if or how they are justified.

\section{Proposal for future work}

In light of our findings, and the discussed complexity of identifying reasons for referral or treatment behaviour, we question if it is possible to identify the effectiveness of IP within the restrictions of currently obtainable metrics. We suggest that to truly identify the impact of changes in optometric referrals by IP, it is necessary to identify what a normal scope of practice for the average reasonable optometrist would be over a calendar year, and then compare and contrast that baseline data with the enhanced scope of practice behaviour for an average reasonable IP optometrist. To this end, we propose a ratio of primary, supplementary, non-referral and referral rates as a better method to further determine the true impact of IP in community optometric behaviour. In our present study, a high supplementary to primary examination ratio, and a low referral to non-referral ratio was 
observed, but that was in the context of the entire community optometry service in Scotland. If these metrics were available for different cohorts of optometrists this breakdown would enable better categorisation of the normal optometric practice, and allow analysis of the impact of changing trends, such as education and training, referral refinement and the potential collateral work generated from new guidelines, such as the SIGN guidelines for glaucoma referral and safe discharge. ${ }^{25}$ As IP becomes more widespread within community optometry, this proposed ratio could be used to discern more accurately the true impact of IP in Scotland. 


\section{Conclusion}

This is the first study of IP optometrists assessing the impact on referral rates in Scotland. There are 1189 community optometrists in Scotland as of March 2019, with 278 holding the IP qualification (23.4\%). Despite good geographical distribution and increased supplementary attendances, optometric referrals to HES continue to rise. The current metrics available will not permit a thorough evaluation of the impact of IP. We propose a ratio of non-referral, supplementary and referral rates to discern the true impact of IP on community optometric behaviour. Further work evaluating the impact of IP on prescribing patterns, patients' perspectives and a detailed cost-benefit analysis of the corresponding demands on the hospital eye services is now required. 


\section{What was known before:}

1. General Ophthalmic Services legislation and Independent Prescribing (IP) for optometrists was introduced to refine and reduce referrals to Hospital Eye Services through optometrists providing initial management.

2. No studies exist to quantify the true impact of IP in Scotland since its' introduction in 2010.

\section{What this study adds:}

1. This is the first analysis of IP optometrists assessing the distribution or impact on referral rates across Scotland. As of March 2019, there were 278 IP-qualified optometrists in Scotland (23.4\%).

2. Despite good geographical distribution and increased supplementary attendances ( $290 \%$ in anterior segment supplementary visits), optometric referrals to HES have doubled and continue to rise.

3. There was no correlation or association that quantity of IP optometrists reduced the referral rate to HES (Pearson correlation co-efficient $r=-0.06,95 \% \mathrm{Cl}-0.64$ to $0.56, p=0.86$ ).

4. We propose a ratio of primary, supplementary, non-referral and referral rates to evaluate the true impact of IP versus non-IP community optometric behaviour. 


\section{References}

1. Scottish Government Health Directorates. General Ophthalmic Services, Scotland. (Queen's Printer for Scotland, 2006).

2. Scottish Government Health Directorates. General Ophthalmic Services, Scotland. Amendment. (2010).

3. NHS Information Services Division. General Ophthalmic Services: Statistics Report. (2018).

4. NHS Education Scotland. Independent Prescribing. Available at: https://www.nes.scot.nhs.uk/education-and-training/by-discipline/optometry/professionaldevelopment/independent-prescribing.aspx. (Accessed: 8th August 2019)

5. General Optical Council. Independent Prescribing. Available at: https://www.optical.org/en/Education/Specialty_qualifications/independentprescribing.cfm. (Accessed: 8th August 2019)

6. General Optical Council. A Handbook in Optometry Specialist Registration in Therapeutic Prescribing. (2008).

7. Needle JJ, Petchey R, Lawrenson JG. A survey of the scope of therapeutic practice by UK optometrists and their attitudes to an extended prescribing role. Ophthalmic Physiol. Opt. 2008;28:193-203.

8. Bolland S, Henderson R, Loffler G, Gordon G. Therapeutic prescribing for optometrists : an initial perspective. Optom. Pract. 2011;12:87-99.

9. Annoh R, Patel S, Beck D, Ellis H, Dhillon B, Sanders R. Digital ophthalmology in Scotland: benefits to patient care and education. Clin Ophthalmol. 2019;13:277-286.

10. NHS Information Services Division. Eye Care Publications. (2018). Available at: https://www.isdscotland.org/Health-Topics/Eye-Care/Publications/datatables2017.asp?Co=Y. (Accessed: 8th August 2019)

11. Legge R, Strang NC, Loffler G. Distribution of optometric practices relative to deprivation index in Scotland. J. Public Health (Oxford). 2018;40:389-396.

12. The College of Optometrists. The Optical Workforce Survey Full Report. (2015).

13. Scottish Government. Introducing The Scottish Index of Multiple Deprivation. (2016).

14. The Scottish Government Publications. Community Eyecare Services: Review. (2017).

15. Ang GS, Ng WS, Azuara-Blanco A. The influence of the new general ophthalmic services (GOS) contract in optometrist referrals for glaucoma in Scotland. Eye (Lond). 2009;23:351-5.

16. NHS Information Services Division. NHS Outpatient Waiting Times for Ophthalmology. (2019).

17. NHS Digital. Hospital Outpatient Activity. (2018). Available at: https://digital.nhs.uk/data-and- 
information/publications/statistical/hospital-outpatient-activity. (Accessed: 4th October 2019)

18. Fung $M$, Myers $P$, Wasala $P$, Hirji N. A review of 1000 referrals to Walsall's hospital eye service. J. Public Health (Oxford). 2019;38:599-606.

19. Pierscionek TJ, Moore JE, Pierscionek BK. Referrals to ophthalmology: Optometric and general practice comparison. Ophthalmic Physiol. Opt. 2009;29:32-40.

20. Todd D, Bartlett H, Thampy R, Dhawahir-Scala F, Wilson H, Tromans C. Agreement in clinical decision-making between independent prescribing optometrists and consultant ophthalmologists in an emergency eye department [published online ahead of print, 2020 Mar 17]. Eye (Lond). 2020;10.1038/s41433-020-0839-7.

21. Lash SC. Assessment of information included on the GOS 18 referral form used by optometrists. Ophthalmic Physiol. Opt. 2003;23:21-23.

22. Evans BJW, Harle DE, Cocco B. Optometric referrals: towards a two way flow of information? Br. J. Ophthalmol. 2005;89:1663.

23. The Royal College of Ophthalmologists. Ophthalmic Services Guidance. Primary Eye Care, Community Ophthalmology and General Ophthalmology. (2019).

24. Low L, O'Colmain U, Ogston S, MacEwen C. Accessibility of high-street optometry premises within Tayside. British Journal of Ophthalmology. 2013;97:1216-1217.

25. Scottish Intercollegiate Guidelines Network. SIGN 144 - Glaucoma Referrals and Safe Discharge. (2015). 
Legend:

Figure 1: Graph showing the percentage share of IP optometrists in each quintile of deprivation (Q1-5) in each health board in 2019. There were no IP optometrists in NHS Orkney, NHS Shetland and NHS Western Isles. The addition of all the bars in one quintile equals $100 \%$. The coefficient of skewness below demonstrates the degree of symmetry of IP optometrists across quintiles of deprivation in each health board.

Figure 2: Graph illustrating the four commonest recorded reasons for supplementary visits since 2010. Anterior segment presentations and sudden visual loss / flashes \& floaters / neurological symptoms represent $68.7 \%$ of all supplementary examinations in $2018 / 19$. Average annual increase is shown on the right. Other recorded reasons for supplementary visits have been excluded as they each make up less than 20,000 visits per year.

Figure 3: Graph showing the increase in referral rates from community optometry to HES in each health board since 2010 . The referral rate for the whole of Scotland has increased from $\mathbf{2 . 5 \%}$ to 4.1\%. The greatest increase was seen in NHS GG\&C and the smallest increase in NHS Forth Valley. Figure 4: Graph showing the correlation between referral rate to HES and the percentage of optometrists who hold the IP qualification for each health board in 2018/19. For all 14 health boards (solid trendline), the Pearson correlation was not significant, $r=+0.53,95 \% \mathrm{Cl}-0.002$ to 0.83, $p=0.052$. Excluding the three health boards with no IP optometrists (dashed trendline), Pearson correlation was $r=-0.06,95 \% \mathrm{Cl}-0.64$ to $0.56, p=0.86$ (still not significant).

Figure 5: Graph showing absolute numbers of community optometry referrals to HES and the number of new patient attendances in HES. The average annual increase in referrals $(\mathbf{1 4 . 8 \% )}$ was not mirrored by a similar increase in new patient HES attendances (1.8\%). This may be suggestive of a lack of capacity / resources in HES.

Supplementary Table 1: Criteria for primary and supplementary eye examinations performed by community optometrists in Scotland - in use from 2010 to September 2018.

Supplementary Figure 1: The number of primary and supplementary eye examinations performed by community optometrists in Scotland. There has been a $18.0 \%$ increase in primary visits and a 93.2\% increase in supplementary visits since the new GOS legislation was introduced in 2010. In total, there has been a $\mathbf{3 0 . 3 \%}$ increase in visits to community optometry. Of note, the IP qualification was introduced in 2008 and the register launched in 2009. 